\title{
Qualitative Methodology: Psychobiography
}

\author{
Jareño Gómez A*, Chíclana Actis C and Noriega García C \\ Department of Psychology and Pedagogy, Spain
}

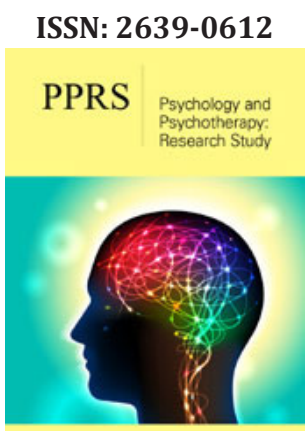

*Corresponding author: Jareño Gómez A, Department of Psychology and Pedagogy, Spain

Submission: 皆 November 11, 2019

Published: 僵 November 20, 2019

Volume 3 - Issue 1

How to cite this article: Jareño Gómez A*, Chiclana Actis C, Noriega García C. Qualitative Methodology: Psychobiography. Psychol Psychother Res Stud. 3(1).PPRS.000555.2019.

DOI: 10.31031/PPRS.2019.03.000555

Copyright@ Jareño Gómez A, This article is distributed under the terms of the Creative Commons Attribution 4.0 International License, which permits unrestricted use and redistribution provided that the original author and source are credited.

\begin{abstract}
The aim of the current article is to explain and define what a psychobiography is and distinguish it from other concepts such as life story, pathography, psychohistory or case study. We review the history of this approach from its origins to the present, showing its evolution and acceptance throughout these years. Afterwards, we explain its predictive, educative and scientific characteristics and we present the main processes to develop a psychobiography. Lastly, the article presents some common criticisms of this approach as well as responses to them.
\end{abstract}

Keywords: Psychobiography; Personality; Personality psychology; Qualitative methodology; Qualitative measures; Qualitative inquiry

\section{Introduction: What is a Psychobiography?}

"A psychobiography can be explained as the efficient use of psychological theory to convert the subject's life into a coherent and illuminating story" [1]. The aim of a psychobiography is the understanding of the person [2]; not to generalize nor to identify commonalities, but to approach each subject as sui generis [3]. The question that it always tries to answer is why, instead of how [4]. As Alexander [5] says, the psychobiographer tends to be interested in understanding the disputed and unexplained aspects of the subject's life. For this reason, careful and direct observation is the main tool used in psychobiography, along with subsequent interpretation, based on existing psychological theories of personality. It is therefore a qualitative research method and, as we will see later, a method that can be developed through many different procedures [6]. Psychobiography focuses on mental resources, personality traits and emotional life, as well as the artistic production of the subject, in case the study is of a genius [4]. Since the researcher is going to develop an empathic relationship with the chosen subject throughout the project in order to go deeper into his psychological functioning, this might lead us to think that psychobiography may come subjective, nevertheless that does not mean a psychobiography cannot be relatively objective too [3].

\section{Conceptual boundary}

We find convenient to distinguish other approaches that on some occasions might confuse researchers due to their similarities with Psychobiography. Life histories and life stories are compilations of autobiographies about a sample of people that share ethnicities, social problems, professions or a specific lifestyle [7]. A psychobiography does not use autobiographies but primary and secondary sources and usually it focuses on one person at a time. Pathography is a medical approach that aims to evaluate the impact of variables such as heritage, development, mental or physical pathology, behavior, decision-making and achievements. The psychiatrist Julius Möbius was the first one to use this term and wrote several pathographies about some of the most influential thinkers such as Rousseau, Goethe, Schopenhauer and Nietzsche [8]. Psychobiography, however, is a psychological approach and it does not search for any mental or physical disorder because a diagnosis is considered a mere description that would not succeed in interpreting the subject's behavior or functioning [2]. Case study is a method which goal is to serve as a guide to decide a treatment for a person. In a case study authors choose some special moments in subjects' lives to shed light on those, in this case, anonymous lives [9]. In contrast, psychobiography is a work that focuses on the subject's development, from his birth to his death and aims to understand the psyche, not to fix it [10]. Psychohistory was born with Erikson and is the application of psychology in understanding the past, paying special attention to group behaviors [8]. 


\section{Origins}

The first one to use this method, which today is known as psychobiography, was Freud, although its true origin comes from Plutarch (between $45 \mathrm{AD}$ and $125 \mathrm{AD}$ ), who focused on politicians and historians. Later, in the $16^{\text {th }}$ century, Giorgio Vasari wrote about the lives of artists [8]. In 1910 Freud published an essay about Leonardo Da Vinci, and years later he wrote other studies on Goethe and Dostoevsky. Following his research, other Psychoanalysis professionals began to use this methodology to approach other artists, such as a study on Shakespeare, written by Jones in 1910 or Wagner which was conducted by Graaf in 1911. However, those works came under considerable criticism as the analyses seemed to be highly influenced by psychopathological aspects [8]. Fortunately, there was a group of Psychoanalysis professionals that worked on clarifying and delimiting the meaning and goal of the psychobiography. Kris wrote the chapter Legend, Myth, and Magic in the Image of the Artist referring to this issue where he mentions the general authors' tendency to search for an explanation of the genius in childhood [11].

Beres shed further light on the methodology by arguing that the researcher must put some boundaries on his or her interest and be careful of identifying himself with the subject or, on the other hand, overturning feelings of hostility. He also emphasized that the connection between psychological features of the subject and or with his artistic production are not always so evident [8]. It was in the 1930s when psychobiography was no longer restricted to theories of psychoanalysis; Personology was a new approach that focused its attention on exploring the subject through his life story and it was promulgated by Allport, who emphasized that life story is the only dimension that helps us to discover one's individuality, because when we talk about human personality, we often refer to the story of that life. Murray, biologist and later a remarkable personality psychologist, also supported Allport's ideas. It was the most important way of working on current psychobiography besides Psychoanalysis [12]. Rosenzweig, Murray's disciple, who was remarkably interested in literature, creativity, history and all possible means of exploring individuality, published several psychobiographies on Freud's journey to America, Henry and William James, Herman Melville, Nathaniel Hawthorne and Lewis Carroll [8]. Erikson went further and suggested the importance of building a bridge between psychology and history. Hence, he was considered the inventor of psychohistory, after publishing works about the characters Gandhi and Luther [8]. Unfortunately, from the second half of the $20^{\text {th }}$ century, especially after World War II, the nomothetic approach, which focuses on coming up with universal rules, became the main approach. Consequently, psychoanalysis and personology were relegated [13]. Nevertheless, in the American personality psychology, a combination of psychodynamic and personology approaches along with narrative psychology was born. According to Runyan, this should be called historical-interpretative psychology. This would be the third way to work on scientific psychology, besides correlational and experimental approaches defined by Cronbach, and it is used in case studies, psychobiographies and life studies in specific social, cultural and historical specific contexts [12]. Nomothetic tendency in personality began to receive criticisms like the one written by Carlson [14] in Where is the person in personality research? With this, and with an increasing understanding and acceptance of life stories analysis from personality psychology and applied psychology, psychobiography started to recover its importance [8].

Thanks to the work of Anderson, Alexander, Runyan, Elms, McAdams and Schultz, among others, psychobiography was strongly reborn in the 1980s. The increasing popularity of narrative psychology contributed to that [8]. Runyan wrote Life histories and Psychobiography: Explorations in Theory and Method [15]. In 1988 McAdams, who integrates narrative psychology and identity theory (by Erikson), published Psychobiography and life narratives in cooperation with Ochberg. McAdams developed a model that can be applied in a psychobiography analysis [16-18]. In the same year, the Journal of Personality published also a monographic number about psychobiography. This would be referred to as the book Psychobiography and life narratives written by McAdams, Elms, Anderson, Runyan, Carlson, Winter and Ochberg among others [2]. Nowadays, there has been an increase of publications about this methodology. Schultz edited and wrote in 2005 the Handbook of psychobiography, a compilation of explanatory chapters in which McAdams, Runyan, Elms, Alexander, Anderson, Ogilvie, Atwook and others have participated [2]. Also, the Handbook of research methods in personality psychology was published. In it there is a specific chapter about psychobiography described by Elms [10]. Only a few months ago, New trends in psychobiography was published, having been edited by Mayer \& Kőváry [19]. Other examples of psychobiographies published in the last 10 years, showing its prolific growth, are the following: Tiny terror: Why truman capote (Almost) wrote answered prayers [20], George W Bush and the redemptive dream: A psychological portrait [21], Lucy in the mind of Lennon [22], A Psychobiography of bobby fischer: Understanding the genius, mystery, and psychological decline of a world chess champion [23], The life of Steve Jobs: a psychobiographical study [24], Creative works of Paulo Coelho: A psychobiography from a positive psychology perspective [25] and Life come shining: the transformations of Bob Dylan [26].

\section{Characteristics, value and applicability of a psychobiography}

As mentioned before, psychobiography, as a qualitative method, tends to focus its attention on the individuality of the subject, considering the whole person [15]. That means it is also essential to consider the socio-historical and cultural information, as well as the social skills and family story [27]. The fact that psychobiography is usually done on deceased people helps to investigate about the patterns in human development along a continuous period. Consequently, it is an opportunity to test and develop new personality and human development theories [28].

Some of the uses of this method are the following:

1. Understanding the unique personality patterns, because, as the author explains, although we know we share certain features with other human beings, we also experience our singularity [10]. 
2. Helping to predict behaviors in, for example, politicians, a traditional interest in psychobiography, in fact, since 1920 these works have been carried out, like the book The Presidential Character, published in 1972 by James David Barber, in which he proposed a typology to categorize US presidents and candidates. More recent is the work about George Bush mentioned above [21].

3. Enriching the subject's understanding by contextualizing it, because psychobiography asks to know and to understand the relevant social and historical environment [7]. Thus, psychobiography offers a holistic description of the subject [28].

4. Validating or rethinking personality theories or approaches. Psychobiography is also a source of several personality theories. Very important psychologists such as Freud, Maslow and Erikson were inspired by specific life stories, like those of Leonardo Da Vinci, Ruth Benedict, Max Wertheimer and Martin Luther King respectively, to build or reconsider their theories [10].

\section{Psychobiography is useful at the educational level.}

In-depth analyses of other lives help psychology students expand their knowledge about the human mind and behavior by integrating and using psychological achievements [8]. Thanks to the study of lives, the psychologist or psychology student deepens the knowledge of another person's psychological functioning and of oneself [2]. It also helps the researcher develop empathy towards the subject he or she is studying [15] a crucial skill in Psychology, especially for future psychotherapists.

\section{How to do a psychobiography}

This article first presents two general guides to orientate the researcher about the process and then a more detailed step by step guide that will help novel psychobiographers or researchers who search for a more solid structure.

Schultz divided the preparation of a psychobiography into four main steps (2):

1. To read about the subject from both first-person and third-person documents.

2. To find a problem to solve or locate a mystery to unveil in the life of this subject.

3. To re-read the biographies and other sources having this mystery in mind. This is a back and forth process.

4. To build the story. Firstly, it is important to talk about the mystery, to add emotion and provoke interest in the reader. Secondly it would be useful to transmit why this topic and subject are so intriguing and important to unveil. According to Schultz, the reader should feel an increasing dramatic tension that will be resolved by its interpretation at the end. The writer should write as an artist not as a scientist.

Elms also wrote a guide to explain this process; in this case, he presented nine general steps (10):

1. To choose a subject: The recommendation is that we should not experience radical feelings, neither idealization nor rejection.

2. To formulate tentative hypotheses: they will probably be modified throughout the research.

3. To collect data from different sources. In a life story it is important to read what that subject produced, his dreams, letters he could have written, to talk with close people to him, etc., [2].

4. Review the first hypotheses now using specific psychological frameworks, such as psychoanalysis, personology, narrative psychology, etc.

5. To develop the focus on the information we have collected and read so far, using models like Alexander's or Schultz's. These two authors suggest criteria to select data more specifically, such as primacy or frequency in Alexander [5], or thrownness in Schultz $[6,29]$.

6. If there is contradictory information, we must rely on the primary sources whenever possible. In case we had to use other sources, we would have to test the attitude of the authors towards the subject in order to know what to believe.

7. To keep trying to find more evidence to justify, refute or modify our previous assumptions.

8. To identify and delimit valid conclusions. The next step will help with this.

9. To find out and read the works about the same subject done by other researchers.

To complete and offer a more detailed structured, Du Plessis [30] adapted Miles, Huberman and Saldaña's indications [31] and proposed a twelve-step guide that may be helpful to those new to researching in particular.

a. Select the subject. Du Plessis recommends answering certain questions about the choice of the subject such as "Why am I selecting this subject?" or "Is this subject of interest to people other than myself?" The cogency of these answers will help to determine if the subject is suitable for a psychobiographical study.

b. Identify primary and secondary sources relating to the subject. At first, it is necessary to identify as many sources as possible. Then, a critical evaluation of their usefulness must be done. As this author emphasizes, the decision in relation to what data should be included or excluded is essential, because it will determine the nature of the psychobiographical study.

c. Identify the context in which the subject lived and determined the amount of contextual data that is needed for the psychobiography. This step will add the accuracy needed for later psychological interpretations.

d. Select an appropriate psychological theory or theories. There are no predetermined models to interpret the information we are going to obtain. However, as Schultz says, the quality of the psychobiography will depend, among other aspects, on the selection of a rigorous theory, scientifically supported [3]. 
e. Allow the data to reveal itself. As mentioned above, the indicators of psychological salience are a very good help in this stage. Alexander and Schultz provide useful markers [5,6,29].

f. Ask the data specific questions relating to the subject being studied. These questions may be related to the selected theory.

g. Develop coding strategies and code the data accordingly. Multiple coding strategies will usually be necessary.

h. Select display formats (use multiple formats if possible).

i. Integrate coding with display.

j. Write up of psychobiography.

k. Revision of psychobiography in relation to specific questions developed previously.

l. Evaluation of research process quality. Several authors such as Elms [32] and Schultz [2,6] offer guidelines to evaluate the quality of the psychobiography.

\section{Criticisms and arguments in favor}

This article shows below the main criticisms that this methodology has received $[9,33]$ along with the answers to those criticisms:

a) Psychobiography is based on retrospective information, since most of the psychobiographies are done on deceased people. Nevertheless, this can be an advantage because one of the risks we take when we work on living people is that some findings about the subject's personality could be embarrassing, and publishing these could cause trouble in the subject's professional and private life [8]. And, what is more important, working on deceased people helps to investigate about the patterns in human development along a continuous period. Therefore, it is a good opportunity to test and develop new personality as well as human development theories $[28,10]$, which will contribute to increase the accuracy of future researches, both nomothetic and idiographic. In relation to what would happen if we find contradictions, Runyan emphasizes that psychobiography is mainly based on primary sources [33]. Elms, who also supports this statement, suggests that in order to discern the truth information first the researcher must consult the primary sources and, if necessary, then read the contemporaries knowing their position towards the subject. If even the subject's contemporaries disagree, Elms proposes that the researcher should trust those who are believed to have benefited least from transmitting information about the subject [10].

b) Psychobiography can be only a first step toward using the scientific method because it helps to formulate hypotheses but not to test them. It is true that universal laws can usually not be established through the study of a particular individual, but laws of the individual can be formulated and tested through rigorous experimental and statistical methods at the level of the individual case [34]. c) Psychobiography has a low external validity because it does not allow generalizations based on a single case. This criticism assumes that the aim of personality psychology is only to produce generalizations at the highest possible level of abstraction, preferably universal generalizations. Nonetheless, personality psychology needs to attend to goals on at least three different levels of abstraction: universals, groups, and individuals. A psychobiography aims not to find general rules but particularities and singularity of a subject [35]. Hence, in response to "How can you generalize from that idiographic study?" we could ask: "how can you particularize from that group or population study?" [34].

d) Psychobiography has a low internal validity since it is possible to find other alternative explanations [9]. It is true that there can be different interpretations for the same subject, but this is part of the essence of this method. To know a person requires interpretation, not variable manipulation [14]. In addition, in order to be rigorous with the method, there are several criteria to establish or select the most suitable explanations for each case, which are the following: the explanation has to be logical; the wide range of aspects of the event or situation in question should survive the falsification tests; this explanation should also show consistency with the relevant available information that exists; it should show consistency with the general knowledge that we have about the operation of the human being or the person in question; and it should show credibility against other explanatory hypotheses [36].

e) The psychobiographical method has also been criticized because there is a large number of them based on psychoanalytic theories [37-39,13]. Currently, however, this has been reduced or complemented with other development or personality theories with more scientific support. Nowadays, psychobiographers have a wide range of theories to apply. The psychobiography will have the credibility of its chosen theory; therefore, it is recommended to select one with enough rigorous support [35].

\section{Conclusion}

Psychobiography is an idiographic approach within the qualitative methodology in personality psychology. As it is searching for the understanding of the person, the why question, instead of the how, psychobiography focuses carefully on mental resources, personality traits and emotional life, interpreting all this information using the existing psychological theories of personality and or development. Because Freud was the first one to use this method, psychobiography has been widely influenced by psychoanalysis for many years. Nowadays, the theory choice is more eclectic, governed by considerations related to scientific merit. Although it would be possible to interpret the data using any personality or development theory, the appropriate thing to do is to always rely on models that are scientifically supported. Elms and Schultz make useful recommendations to carry out a psychobiography, being essential to remember the importance of selecting both first-person and third person documents to extract reliable information and that this method is a back and forth process. 
Thank to du Plessis we also now have a step-by-step guide from the selection of the subject to the evaluation and revision of the process, that will help to structure and give rigor to future psychobiographies. A good knowledge of the goal that a psychobiographical study pursues as well as of the tools that are used in the face of potential difficulties during the process allows to discuss and to offer solid arguments to the criticisms received. The psychobiography, therefore, is a useful qualitative method to obtain a better understanding of the unique personality patterns and predict behaviors, as well as for theorists to rethink or validate their personality theories or approaches. Due to the immersion of the researcher in this type of study this method enables him to go deeper into the subject's psychological functioning, including the functioning of oneself.

\section{References}

1. McAdams DP (1988) Biography, narrative, and lives: An introduction. Journal of Personality 56(1): 1-18.

2. Schultz WT (2005a) Introducing Psychobiography. In: Schultz WT (Ed.), Handbook of Psychobiography. Oxford University Press, New York, USA, pp. 3-18.

3. Schultz WT (2016) Psychobiography: Theory and practice. The American Psychologist 72(5): 434-445.

4. Schultz WT (2014) The Psychobiography of Genius. In: Simonton DK (Ed.), The Wiley Handbook of Genius. John Wiley \& Sons, Chichester, UK, pp. 20-32.

5. Alexander I (1990) Personology: Method and content in personality assessment and psychobiography. Duke University Press, Durham and London, UK.

6. Schultz WT (2005b) How to strike psychological pay dirt in biographical data. In: Schultz WT (Ed.), Handbook of Psychobiography, Oxford University Press, New York, USA, pp. 42-63.

7. Fouché JP, Van Niekerk R (2005) Psychobiography: An interdisciplinary approach between psychology and biography in the narrative reconstruction of personal lives. International Society for Theoretical Psychology, Cape Town University, South Africa.

8. Kováry Z (2011) Psychobiography as a method, the revival of studying lives: New perspectives in personality and creativity research. Europe's Journal of Psychology 7(4): 739-777.

9. Ruiters JJ (2013) Michael Jackson: A psychobiography. Rhodes University, South Africa.

10. Elms AC (2007) Psychobiography and case study methods. In: Robins RW, Fraley RC, Krueger RF (Eds.), Handbook of research methods in personality psychology. Guildford Press, New York, NY, USA, pp. 97-113.

11. Kris E (2000) Psychoanalytic explorations in art. International Universities Press, Madison, Connecticut, USA.

12. Runyan WM (2005a) Evolving conceptions of psychobiography and the study of lives. In: Schultz WT (Ed.), Handbook of psychobiography. Oxford University Press, New York, USA, pp. 137-159.

13. Runyan WM (1997) Studying lives. Psychobiography and the conceptual structure of personality psychology. In: Hogan R, Johnson J, Briggs $S$ (Eds.), Handbook of personality psychology. Academic Press, California, USA, pp. 41-69.

14. Carlson $\mathrm{R}$ (1971) Where is the person in personality research? Psychological Bulletin 75(3): 203-219.

15. Runyan WM (1984) Life histories and psychobiography: Exploration in theory and method. Oxford University Press, New York, USA.

16. McAdams DP (2001) The psychology of life stories. Review of General Psychology 5(2): 100-122.

17. McAdams DP (2005) What psychobiographers might learn from personality psychology. In: Schultz WT (Ed.), Handbook of Psychobiography. Oxford University Press, New York, USA, pp. 64-83.

18. McAdams DP, Pals JL (2007) The role of theory in personality research. In: Robins RW, Fraley RC, Krueger RF (Eds.), Handbook of research methods in personality psychology. Guildford Press, New York, USA, pp. 3-20.

19. Mayer C, Kováry Z (2019) New trends in psychobiography. Springer Nature Switzerland, Cham, Switzerland.

20. Schultz WT (2011) Tiny terror: Why truman capote (almost) wrote answered prayers. Oxford University Press, New York, USA.

21. McAdams, Dan P (2010) George W Bush and the redemptive dream: A psychological portrait. Oxford University Press, New York, NY, USA.

22. Kasser T (2013) Lucy in the mind of Lennon. Oxford University Press, New York, USA.

23. Ponterotto JG (2012) A Psychobiography of bobby fischer: Understanding the genius, mystery, and psychological decline of a world chess champion. Charles C Thomas Publisher, Springfield, Illinois, USA.

24. Du Plessis R (2016) The life of Steve Jobs: A psychobiographical study. University of the Free State, Bloemfontein, South Africa.

25. Mayer C (2017) The life and creative works of Paulo Coelho: A psychobiography from a positive psychology perspective. Springer Nature Switzerland, Cham, Switzerland.

26. McCarron A (2017) Light come shining: The transformations of Bob Dylan. Oxford University Press, New York, USA.

27. Roberts B (2002) Biographical research. Open University Press, Buckingham, England.

28. Carlson R (1988) Exemplary lives the uses of psychobiography for theory development. Journal of Personality 56(1): 105-138.

29. Schultz WT (2003) The prototypical scene: A method for generating psychobiographical hypotheses. In: Josselson R (Ed.), Up close and personal: The teaching and learning of narrative research. APA Books, Washington DC, USA, pp. 151-176.

30. Du Plessis C (2017) The method of psychobiography: Presenting a stepwise approach. Qualitative Research in Psychology 14 (2): 216-237.

31. Miles MB, Huberman AM, Saldana J (2014) Qualitative data analysis: A methods sourcebook. Sage Publications, Los Angeles, USA.

32. Elms AC (2005) If the glove fits: The art of theoretical choice in psychobiography. In: Schultz WT (Ed.), Handbook of psychobiography. Oxford University Press, New York, USA, pp. 84-95.

33. Runyan WM (1982) In defense of the case study method. Am J Orthopsychiatry 52(3): 440-446.

34. Runyan WM (1983) Idiographic goals and methods in the study of lives. J Pers 51(3): 413-437.

35. Schultz WT, Lawrence S (2017) Psychobiography: Theory and method. American Psychologist 72(5): 434-445.

36. Runyan WM (2005b) How to critically evaluate alternative explanations of life events. The case of Van Gogh's ear. In: Schultz WT (Ed.), Handbook of Psychobiography. Oxford University Press, New York, USA, pp. 96-103.

37. Elms AC (1994) The psychologist as biographer. In: Elms AC (Ed.), Uncovering lives: The uneasy alliance of biography and psychology. Oxford University Press, New York, USA, pp. 3-18. 
38. Ponterotto JG (2014) Best practices in psychobiographical research. Qualitative Psychology 1(1): 77-90.
39. Ponterotto JG (2015) Psychobiography in psychology: Past, present and future. Journal of Psychology in Africa (Routledge), 25(5): 379.

For possible submissions Click below: 